\title{
A Further Study on the Actions of Phenethylguanidine on the Neuromuscular Junction in Frog Sartorius
}

\author{
Akinori Nishiyama \\ Department of Applied Physiology, Tohoku University School \\ of Medicine, Sendai
}

\begin{abstract}
Nrshryama, A. A further Study on the Actions of Phenethylguanidine on the Neuromuscular Junction in Frog Sartorius. Tohoku J. exp. Med., 1973, 111 (1), 15-23 — The active phase (end-plate current) of the end-plate potential, and the relationship between the amplitude of the end-plate potential or the endplate current and the membrane polarization produced by passing current across the muscle membrane were studied in frog sciatic nerve-sartorius treated with $P G$ (phenethylguanidine), which seems to have both competitive and noncompetitive receptor-blocking actions. The falling phase of the end-plate current in PG was slightly but clearly prolonged as compared with that in dTc, a typical competitive receptor blocking agent. The equilbirium potential obtained by the collision experiment (del Castillo and Katz 1954) in PG was found to be at about $-15 \mathrm{mV}$, suggesting that $\mathrm{PG}$ did not influence significantly the ratio $\mathrm{P}_{\mathrm{Na}} / \mathrm{P}_{\mathrm{K}}$ raised by $A C h$ at the end-plate membrane. However, the equilibrium potential was not determined by membrane polarization produced by passing the current across the membrane. Amplitudes of both end-plate potential and end-plate current were increased with muscle membrane depolarization and were decreased with hyperpolarization. Possible factors which may account for these relationships are discussed. - phenethylguanidine; active phase of end-plate potential; relation between end-plate potential or end,plate current and muscle membrane polarization
\end{abstract}

Electrically the motor end-plate can be described as an electromotive force (equilibrium potential, $-15 \mathrm{mV}$ inside) and a series resistance. The mode of action of $\mathrm{ACh}$ on the motor end-plate is to decrease the series resistance whereby electrical change is transferred in the inward direction through this shunting resistance causing outward current flow through the adjoining membrane resulting in its depolarization (Fatt and Katz 1951). Takeuchi and Takeuchi (1959) confirmed, using a voltage clamp technique, that the active phase of the frog endplate potential lasts 5 msec during normal transmission, and that the change in series resistance is independent of the membrane potential. Furthermore, Takeuchi and Takeuchi (1960) showed that the series resistance change produced by ACh at the end-plate membrane is due to both sodium and potassium permeability increase, with the ratio $\mathbf{P}_{\mathrm{Na}} / \mathbf{P}_{\mathrm{K}}$ constant.

These figures mentioned above apply to the curarized muscle, dTc decreases the magnitued of the permeability increase to cations produced by $\mathrm{ACh}$ but has no influence on the ratio $\mathrm{P}_{\mathrm{N}_{\mathrm{a}}} / \mathrm{P}_{\mathrm{K}}$, and therefore also no influence on the equilibr-

Received for publication, Feburary 6, 1973 
ium potential of the end-plate current or the end-plate potential (Takeuchi and Takeuchi 1960). Another interesting fact about the action of dTc is that dTc shortens the time course, especially the falling part of the active phase (Kuffler 1942; Takeuchi and Takeuchi 1959). In the previous paper (Nishiyama and Kuwabara 1973), PG (phenethylguanidine) was found to act on the end-plate partly by a competitive and partly by a noncompetitive receptor-blocking action. Since the mode of action of $P G$ is somewhat different from that of $\mathrm{dTc}$, it was decided in the present experiments to compare the active phase and the equilibrium potential of the end-plate potential in PG with those in dTc. The experimental results indicate that the active phase of the end-plate potential in PG is slightly longer than that in $\mathrm{dTc}$, and that the end-plate potential in PG is decreased with membrane hyperpolarization and increased with depolarization, and thus the equilibrium potential cannot be extrapolated by this relationship. The explanation for these results has not been resolved.

\section{Methods}

The experimental methods for measuring the end-plate potential in frog sartorius muscle were essentially the same as those of our previous report (Nishiyama and Kuwabara 1973).

For the measurement of the active phase of the end-plate potential, the end-plate current was recorded with a modified voltage clamp method similar to that of Takeuchi and Takeuchi (1959). The feed-back amplifier was composed of three stages. The first and second were $\mathrm{DC}$ coupled and the final stage was an $\mathrm{AC}$ coupled differential amplifier with a time constant of $2.0 \mathrm{sec}$. This feed-back amplifier was sufficient for the present experiment in which the clamping time was short (about $15 \mathrm{msec}$ ). The sciatic nerve was stimulated so that the end-plate current appeared within a few msec after the feed-back circuit was closed. As shown in Table 1, the time course of the end-plate current obtained with this circuit was similar to that of Takeuchi and Takeuchi (1959). Some slight discrepancies might be due to differences in the experimental conditions.

For the determination of the equilibrium potential of the end-plate potential, two different methods were used. In one, the equilibrium potential was determined by collision experiment, i.e., by superimposing the end-plate activity on the repolarization phase of muscle action potential (del Castillo and Katz 1954). In this experiment, the preparation was perfused with a hypertonic saline solution containing $230 \mathrm{mM}-\mathrm{NaCl}, 2.0 \mathrm{mM}-\mathrm{KCl}, 5.4$ $\mathrm{mM}-\mathrm{CaCl}_{2}, 0.9 \mathrm{mM}-\mathrm{MgCl}_{2}$, and $1.0 \mathrm{mM}-\mathrm{Na}_{2} \mathrm{HPO}_{4}$, to avoid contraction of the muscle fiber during the action potential. In the other, the equilibrium potential was extrapolated from the relationship between the amplitude of the end-plate potential or the end-plate current and membrane polarization (Fatt and Katz 1951; Takeuchi and Takeuchi 1959).

$P G$ was used in the concentrations of $1.0 \times 10^{-5} \mathrm{~g} / \mathrm{ml} \sim 4.0 \times 10^{-5} \mathrm{~g} / \mathrm{ml}$. These concentrations were rather lower than those in the previous paper (Nishiyama and Kuwabara 1973), and a weak muscle contraction was still observed by neural stimulation in some preparations.

TABLE 1. Time courses of end-plate currents with three different receptorblocking agents. All values are mean values (msec).

\begin{tabular}{ccccc}
\hline Receptor-blocking agent & Rise time & $50 \%$ fall time & Total time & $\mathrm{n}$ \\
\hline $\mathrm{PG}$ & 0.8 & 1.3 & 5.6 & 12 \\
dTc & 0.8 & 0.7 & 4.2 & 18 \\
SCh & 0.8 & 0.9 & 4.6 & 7 \\
\hline
\end{tabular}




\section{Results}

\section{Active phase of end-plate potential (end-plate current)}

The time course of the end-plate current with three different types of receptorblocking agents is shown in Table 1. The active phase obtained in the curarized muscle at $20-22^{\circ} \mathrm{C}$ was slightly shorter with respect to the $50 \%$ fall time than that at $17^{\circ} \mathrm{C}$ obtained by Takeuchi and Takeuchi (1959).
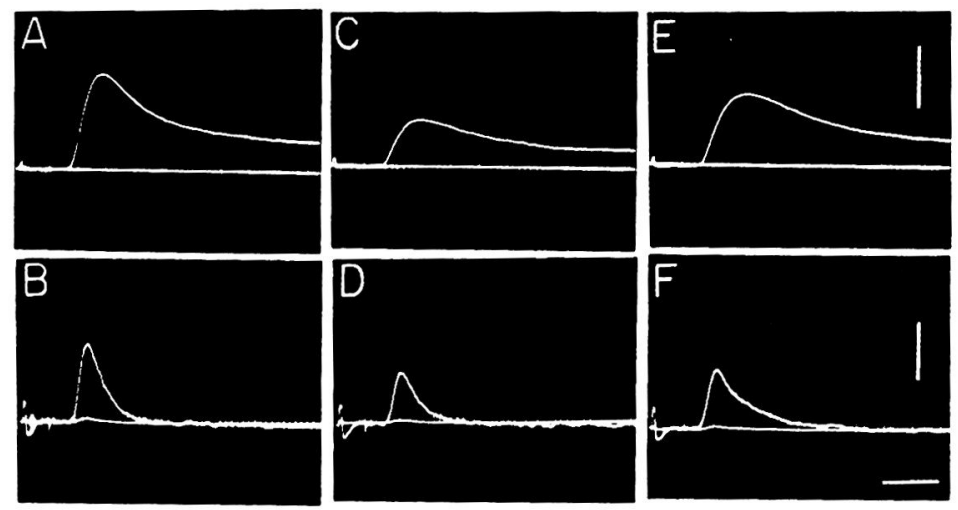

Fig. 1. End-plate potentials (upper records) and end-plate currents (lower records) before and after changing the external medium from a solution containing dTc in a concentraction of $3.0 \times 10^{-6} \mathrm{~g} / \mathrm{ml}$ to one containing $P G$ in a concentration of $4.0 \times 10^{-5} \mathrm{~g} / \mathrm{ml}$. $\mathrm{A}, \mathrm{B}$, in dTc and C, D, E, F, in PG. The amplitudes of both the end-plate potential and end-plate current declined initially for 2-3 min after changing the solution to the $\mathrm{PG}$ one as shown in $\mathrm{C}$ and $\mathrm{D}$, but then recovered gradually leading to steady sizes $(\mathrm{E}, \mathrm{F})$. Voltage scale in upper record, $10 \mathrm{mV}$. Current scale in lower record, $10^{-7} \mathrm{~A}$. Time scale, 2 msec. Resting potential, $-80 \mathrm{mV}$. $\mathrm{Ca}^{2+}, 5.4 \mathrm{mM}$.

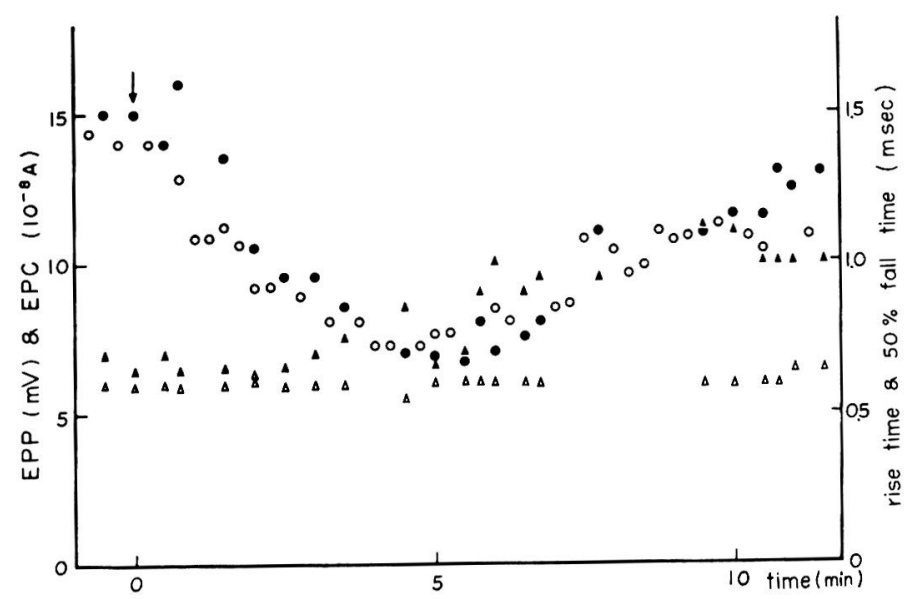

Fig. 2. Time courses of changes in amplitude of end-plate potential (open circle) and endplate current (filled circle), rise time (open triangle) and $50 \%$ fall time (filled triangle) before and after changing the external medium from dTc to PG. The same preparation as in Fig. 1. Note a progressive increase in $50 \%$ fall time in PG. 

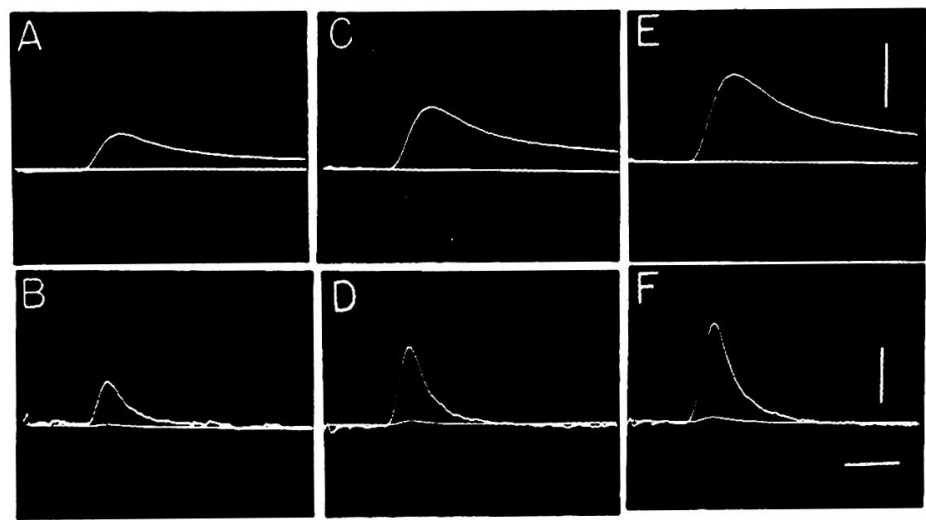

Fig. 3. End-plate potentials (upper records) and end-plate currents (lower records) before and after changing the concentration of dTc from $2.4 \times 10^{-6} \mathrm{~g} / \mathrm{ml}$ to $1.2 \times 10^{-5} \mathrm{~g} / \mathrm{ml}$. $\mathrm{A}, \mathrm{B}$, before and C, D, E, F, after changing the concentration. Note that the time course of each end-plate current was essentially the same nervertheless amplitudes of end-plate potential and end-plate current were different. Voltage scale in upper record, $5 \mathrm{mV}$. Current scale in lower record, $10^{-7} \mathrm{~A}$. Time scale, 2 msec. Resting potential, $-70 \mathrm{mV}$. $\mathrm{Ca}^{2+} 5.4 \mathrm{mM}$.

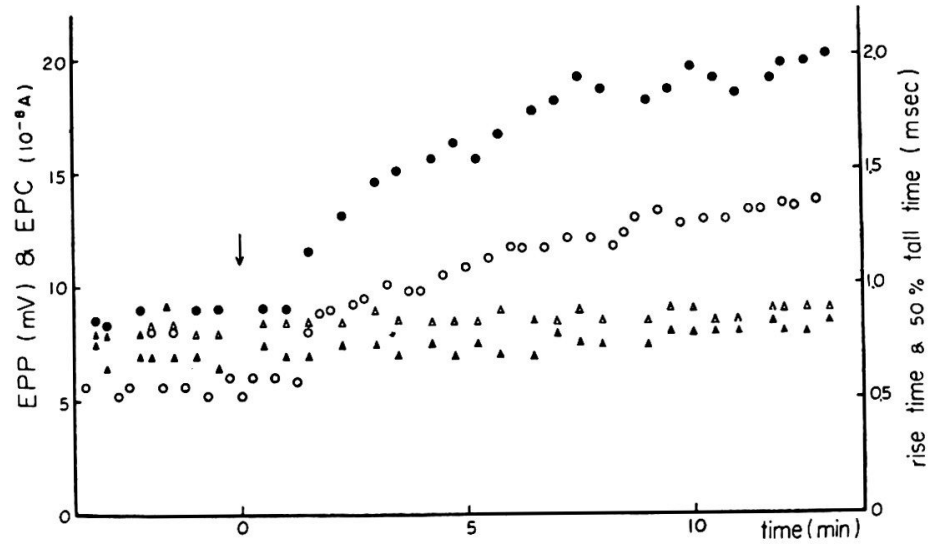

Fig. 4. Time courses of changes in the amplitude of the end-plate potential (open circle) and the end-plate current (filled circle), rise time (open triangle) and $50 \%$ fall time (filled triangle) before and after changing the concentration of dTc from $2.4 \times 10^{-6} \mathrm{~g} / \mathrm{ml}$ to $1.2 \times 10^{-6} \mathrm{~g} / \mathrm{ml}$. The same preparation as in Fig. 3 .

The active phase of the end-plate potential in $\mathrm{PG}$ was somewhat longer than that in dTc. Both the $50 \%$ fall time and total duration were slightly prolonged as compared with those in dTc, while the rise time was the same as in dTc. This was confirmed by recording the end-plate current before and after application of $\mathrm{PG}$ as shown in Figs. 1 and 2. After changing the solution from a dTc containing saline to a $\mathrm{PG}$ containing one, both the $50 \%$ fall time and total duration were prolonged. It was clear from Fig. 1 and 2 that this prolongation was not due to a change in the size of the end-plate potential or the end-plate current. Further- 
more, the time course of the end-plate current in various concentrations of dTc was fairly constant and did not vary with the size of the end-plate potential or the end-plate current as shown in Figs. 3 and 4.

\section{Membrane polarization and end-plate potential or end-plate current}

The amplitudes of both end-plate potential and end-plate current in dTc were decreased with depolarization and were increased with hyperpolarization, and the
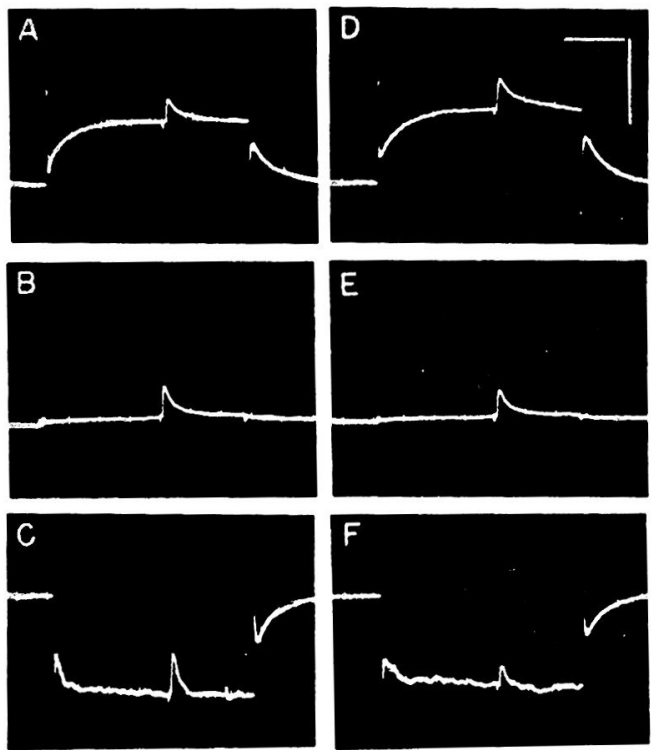

Fig. 5. End-plate potentials from an end-plate at various membrane potentials in dTc $\left(1.5 \times 10^{-6} \mathrm{~g} / \mathrm{ml}\right)$ and in PG $\left(3.0 \times 10^{-5} \mathrm{~g} / \mathrm{ml}\right)$. Left, in $\mathrm{dTc}$ and right, in PG. The membrane potentials were altered by passing current through the second microelectrode. Voltage scale, $25 \mathrm{mV}$. Time scale, $40 \mathrm{msec}$. Resting potential, $-90 \mathrm{mV}$. $\mathrm{Ca}^{2+}, 5.4 \mathrm{mM}$.

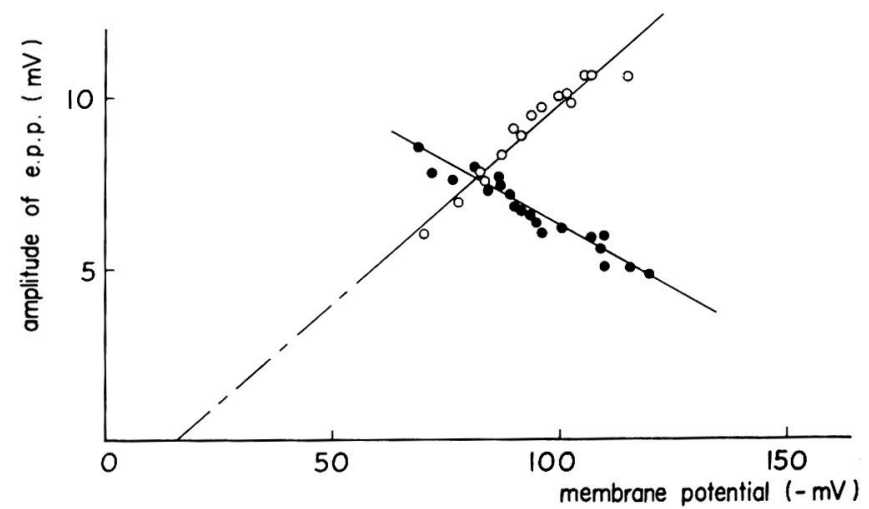

Fig. 6. Relation between the amplitude of end-plate potential and membrane potential in dTc and in PG. Open circles were obtained from an end-plate in dTc and filled circles were obtained from the same end-plate in PG. The same preparation as in Fig. 5. 

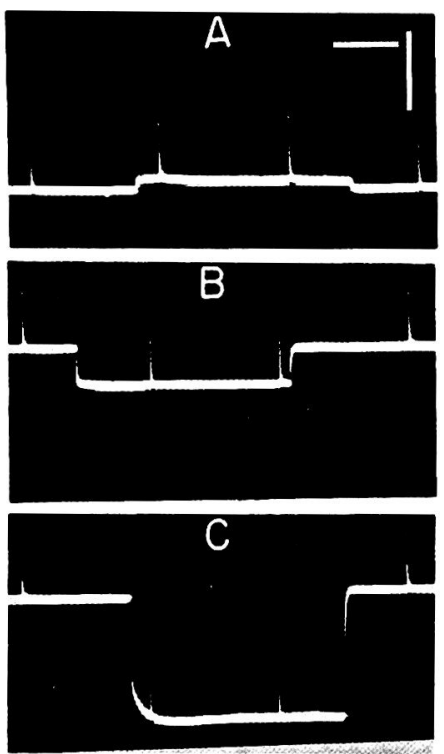

Fig. 7. End-plate potentials recorded from an end-plate at various membrane potentials in $\mathrm{PG}$ at a concentration of $3.0 \times 10^{-5} \mathrm{~g} / \mathrm{ml}$. A similar experiment with that of Figs. 1 and 2 , but the duration of the passed current through were far longer than that of Figs. 1 and 2. Voltage scale, $25 \mathrm{mV}$. Time scale, $2.0 \times$ sec. Resting potential, $-80 \mathrm{mV}$. $\mathrm{Ca}^{2+}$, $3.6 \mathrm{mM}$.

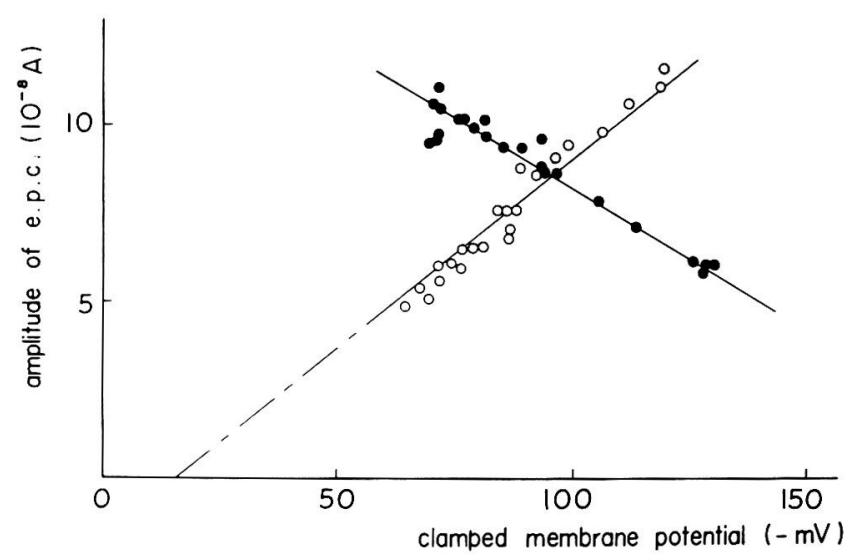

Fig. 8. Relation between amplitude of the end-plate current and membrane potential in dTc at a concentration of $1.2 \times 10^{-6} \mathrm{~g} / \mathrm{ml}$ and in $\mathrm{PG}$ at a concentration of $4.0 \times$ $10^{-5} \mathrm{~g} / \mathrm{ml}$. Open circles were obtained from an end-plate in dTc. Resting potential, $-90 \mathrm{mV}$. Filled circles were obtained from another end-plate in PG. Resting potential, $-72 \mathrm{mV}$. $\mathrm{Ca}^{2+}, 5.4 \mathrm{mM}$.

relationships were linear. If the lines were extrapolated, both lines crossed at about $15 \mathrm{mV}$ negative to the outer saline solution (Fig. 5 left, Fig. 6 open circle, and Fig. 8 open circle). These results agree to those of Takeuchi and Takeuchi (1959). The same relationships were obtained in the end-plates treated with SCh, a depolarizing receptor-blocking agent. 
In contrast to the results obtained in $\mathrm{dTc}$ or in $\mathrm{SCh}$, the relation between the end-plate potential and the membrane potential in PG was inversely proportional, i.e., the end-plate potential was increased with depolarization and was decreased with hyperpolarization (Fig. 5 right, and Fig. 6 closed circle). This change in the size of the end-plate potential appeared immediately after the polarization began and remained almost constant during the period of polarization and returned to the control level as soon as the polarization was turned off (Fig. 7). Furthermore, the relation between the amplitude of the end-plate current and the membrane potential, in which it was unnecessary to consider the electrical characteristics of the muscle membrane around the end-plate (Takeuchi and Takeuchi 1959), was the same as that between the end-plate potential and membrane potential as shown in Fig. 8 (closed circle).

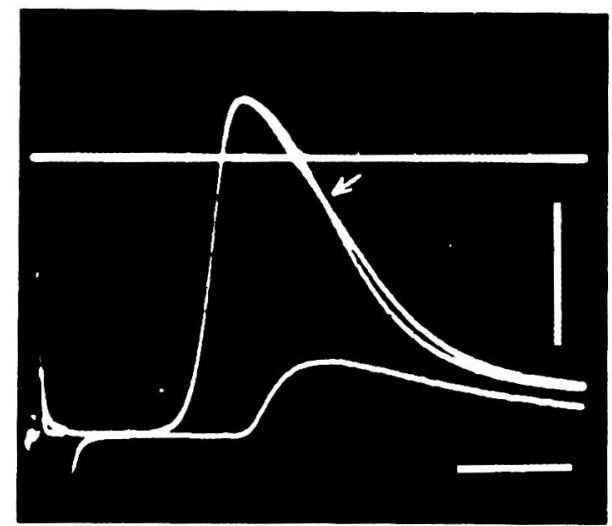

Fig. 9. Direct muscle action potentials with and without end-plate potential in $P G$ at a concentration of $2.0 \times 10^{-5} \mathrm{~g} / \mathrm{ml}$. Voltage scale, $50 \mathrm{mV}$. Time scale, 2 msec. Resting potential, $-90 \mathrm{mV}$. Equilibrium potential, about $-13 \mathrm{mV}$. NaCl, $230 \mathrm{mM}$, $\mathrm{Ca}^{2+}, 5.4 \mathrm{mM}$.

Therefore, the equilibrium potentials of both the end-plate potential and endplate current could not be extrapolated by these lines. However, comparing the action potential set up by stimulation alone with the one, in which the end-plate potential was superimposed, the equilibrium potential of the end-plate potential in $P G$ was found not to be significantly different from those in dTc or those in normal saline solution (Fig. 9). The evidence suggests that PG might act somewhere in the end-plate, leading to a reduction in the increase in permeability to both sodium and potassium ions, but does not affect the ratio of $\mathrm{P}_{\mathrm{Na}} / \mathrm{P}_{\mathrm{K}}$ which is increased by ACh.

\section{Discussion}

There are several factors which determine the time course of the active phase as discussed by Takeuchi and Takeuchi (1959). They described that the falling 
phase of the normal end-plate current was somewhat slower than that of the curarized end-plate current and that dTc might shorten the time course of the end-plate current perhaps by competing with the receptor in the end-plate for ACh. The time course of the end-plate current in PG was rather similar to that of the normal one reported by Takeuchi and Takeuchi (1959). Therefore, the slower time course of the end-plate current in $\mathrm{PG}$ may be due to a non-competitive action of $P G$, which is supposed to interact with a receptor other than that at which the transmitter acts.

Another possibility is that $P G$ acts on the process of liberation of the transmitter from the nerve terminals. Guanidine itself increases the quantity of transmitter released per nerve impulse (Otsuka and Endo 1960), and some guanidino-derivatives also potentiate the neuromuscular transmission (Ozawa and Takeda 1965). Therefore, it is possible that $P G$ acts on the presynaptic site and increases the transmitter output. Tetraethylammonium (TEA), which prolongs the duration of the presynaptic nerve action potential, increases the size of the end-plate potential with a decrease in postsynaptic sensitivity to ACh (Koketsu 1958). Thesleff and Quastel (1965) described that the prolongation of the duration of the action potential might increase fractional release and thus the number of quanta per impulse. Takeuchi and Takeuchi (1959) also suggested an intimate relationship between the time course of the end-plate current and that of the nerve impulse. It is not clear whether PG influences the time course of the action potential of nerve terminals, since it did not influence the nerve action potential recorded with a sucrose-gap method although $P G$ prolonged slightly the duration of the muscle action potential (Nishiyama and Kuwabara 1973).

Although a reasonable explanation which accounts for the inverse relationship between the membrane polarization and end-plate potential or end-plate current in PG has not been obtained, this might be due to either change in liberation of the transmitter from the nerve terminals or in some step of the postsynaptic process, which begins with the interaction of $\mathrm{ACh}$ with its receptor and ends by the increase in the membrane permeability to cations.

Takeuchi and Takeuchi (1961) reported a reduction of transmitter output with hyperpolarization in high potassium media. Recently, Maeno, Edward and Hashimura (1970) have observed that the change in amplitude of the end-plate potential with hyperpolarization was smaller than that of depolarization in a muscle treated with procaine. They concluded that the nonlinear relationship was due to a reduction of ACh output with hyperpolarization, and that the postsynaptic process might be independent of the muscle membrane potential.

On the other hand, Kordas (1969) suggested the possibility that the relationship obtained in glycerol treated muscle, which is similar to that in procaine, might be explained by a change in the receptor-ACh interaction. It is possible that the polarizing current changes the interaction of positively charged $P G$ with some receptor in the end-plate directly or by altering the concentration of PG at the surface of the end-plate. 


\section{Acknowledgment}

I wish to thank Dr. O.H. Petersen for his help in preparation of the manuscript, and Prof. T. Suzuki for discussion on this work, Dr. T. Sakurai for providing the voltage clamp circuits and Mr. R. Sato for his fine technical assistance. Phenethylguanidine was kindly supplied by Prof. H. Ozawa, Department of Chemical Pharmacology, Tohoku University School of Pharmacy.

\section{References}

1) del Castillo, J.\& Katz, B. (1954) The membrane change produced by the neuromuscular transmitter. J. Physiol., 125, 546-565.

2) Fatt, P. \& Katz, B. (1951) An analysis of the end-plate potential recorded with an intracellular electrode. $J$. Physiol., 115, 320-370.

3) Koketsu, K. (1958) Action of tetraethylammonium chloride on neuromuscular transmission in frogs. Amer. J. Physiol., 193, 213-218.

4) Kordas, M. (1969) The effect of membrane polarization on the time course of the end-plate current in frog sartorius muscle. J. Physiol., 204, 493-502.

5) Kuffer, S.W. (1942) Further study on transmission in an isolated nerve-muscle fibre preparation. J. Neurophysiol., 5, 309-322.

6) Maeno, T., Edwards, C. \& Hashimura, S. (1970) Difference in effects on end-plate potentials between procaine and lidocaine as revealed by voltage-clamp experiments. J. Neurophysiol., 34, 32-46.

7) Nishiyama, A. \& Kuwabara, M. (1973). Neuromuscular blocking action of phenethylguanidine in frog sartorius muscle. Tohoku $J$. exp. Med., 111, 1-14.

8) Otsuka, M. \& Endo, M. (1960) The effect of guanidine on neuromuscular transmission. $J$. Pharmacol. exp. Ther., 128, 273-282.

9) Ozawa, H. \& Takeda, M. (1965) Studies on muscle relaxants and their antagonists. V.; The structure-activity relationship and the mode of action of monoguanidino compounds on skeletal muscle. Yakugaku Zasshi, 85, 991-995.

10) Takeuchi, A. \& Takeuchi, N. (1959) Active phase of frog's end-plate potential. $J$. Neurophysiol., 22, 395-411.

11) Takeuchi, A. \& Takeuchi, N. (1960) On the permeability of end-plate membrane during the action of transmitter. J. Physiol., 154, 52-67.

12) Takeuchi, A. \& Takeuchi, N. (1961) Changes in potassium concentration around motor nerve terminals, produced by current flow, and their effects on neuromuscular transmission, J. Physiol., 155, 46-58.

13) Thesleff, S. \& Quastel, D.J.M. (1965) Neuromuscular pharmacology. Ann. Rev. Pharmacol., 5, 263-284. 